\title{
On the Chinization of International Luxuries
}

\author{
How to play the role of Chinese electronic commerce
}

\author{
Dun Lin \\ School of Media Studies \& Humanities \\ Zhejiang University City College \\ Hangzhou, China \\ 549680727@qq.com
}

\author{
Bin Huang \\ School of Media Studies \& Humanities \\ Zhejiang University City College \\ Hangzhou, China \\ huangbin@zucc.edu.com
}

\begin{abstract}
Under the environment of global economic downturn and European debt crisis in recent years, the international luxury brands still have maintained a rapid growth in China. By the end of December 2011, China had become the consumer country with the largest share of luxuries in the world. More and more international luxury brands are entering the competition for the Chinese market, and promoting localized practices in line with Chinese national conditions, and hence the Chinese tendency of international luxuries has become increasingly evident. Based on the development status of international luxuries in China as well as the development condition of the Chinese electronic commerce for luxuries, this paper explores how can the international luxuries cooperate with Chinese electronic commerce and play their roles in the process of chinization.
\end{abstract}

Keywords- international luxuries; luxury consumption; luxury electronic commerce; chinization

*Dun Lin is the first author; Bin Huang is the correspondence author

\section{INTRODUCTION}

As an exotic concept, the international definition for luxury is: "a consumer product that exceeds the range of people's survival and development needs, and it is with unique, scarce and precious features"; hence it is also known as non-necessities. In August 2012, Pushway Marketing Consultancy Organization, a wellknown marketing service provider, cooperated with Research Center on Chinese Brand Map and Chinese High-end Brands to publish The Ranking List of Global Luxuries in 2012, which graded the luxury brands. According to the indicators like status, influence, luxury degree, historical duration, consumer word-of-mouth, popular degree and network attention, luxury brands are divided into first, second and third classes. The international luxury brands this paper is to explore is mainly the first-class ones divided in as the above indicators, which are commonly referred to as "the first-line big brands".

In order to share more market in China, it is necessary for international luxury brands to introduce localized practices in line with Chinese national conditions, and cooperation with the Chinese electronic commerce has become a shortcut.

\section{THE NECESSITY OF CHINIZATION OF INTERNATIONAL LUXURIES}

The global market territory of luxury brands is changing, and the Asia-Pacific market has gradually become strategic places that luxury brands compete for. Among them, the performance of the Chinese market is more prominent. World Luxury Association China latest decade luxury official report: By the end of December 2011, the total annual consumption of Chinese luxury market had reached \$ 12.6 billion (not including private planes, yachts and luxury cars), accounting for $28 \%$ of the global share. This set of data shows that China has become the consumer country with the largest share of luxuries in the world. In addition, according to the forecast of the Wealth Quality Research Institute, in the next 3-5 years, the sales proportion of various luxury groups in the Asia-Pacific region is expected to account for half of the total amount, and maintain a market growth of $20 \%-30 \%$ annually.

The capacity and potential of the Chinese luxury market has become an open secret and hence a growing number of international luxury brands are beginning to enter the battle for the Chinese market. In this battle, those who understands China better and who pushes the localized practices more in line with Chinese national conditions is likely to obtain the final victory. Therefore, the chinization of international luxuries is urgent.

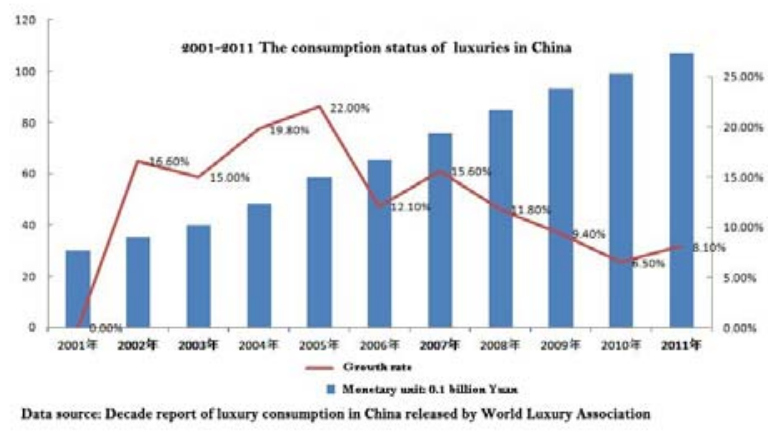

Figure1. 2001-2011 The consumption status of luxuries in China 


\section{THE DEVELOPMENT STATUS OF INTERNATIONAL} LUXURIES IN CHINA

On April 28, 2010, the famous international luxury brand LV (Louis Vuitton) opened two flagship stores in Shanghai. Before this, the world's largest luxury company-French LVMH Group (LV owner) bought a piece of land together with Macau casino tycoon Stanley Ho to build a luxury center. These facts are enough to illustrate the rapid development of the international luxuries in China. The development momentum makes people can not help exclaiming: "Chinese luxury era is coming!” It is said that the monthly cash flow of an LV store is about 3 million Yuan which is conservative estimation. Facing such high profits, the major international luxury brands make various efforts to seize the Chinese luxury market.

In order to meet the needs of more Chinese luxury proponents for the plebification of luxuries, many old international luxury brands have launched sub-line products. For instance, Armani launched a more populist sub-line brand of $\mathrm{A} / \mathrm{X}$. Some luxury brands even create new luxury brands for Chinese consumers. "Shang Xia" brand launched by Hermès only for the Chinese market is one of the typical representatives.

International luxury brands in China also show a concentrated and win-win trend. Take the Shin Kong Place in Beijing for example, it gathers flagship stores of Prada, Chanel, Gucci, Coach, Hugo Boss and other well-known international brands within the area of $173,000 \mathrm{~m} 2$. It is said that these flagship stores will achieve "zero-day" on products, that is, the new products in every season are displayed at the same time with those in New York or Paris.

\section{THE STATUS OF THE CHINESE ELECTRONIC COMMERCE FOR LUXURIES}

Like other electronic commerce enterprises, luxury electronic commerce in China is also exotic. Early in 2001 France opened luxury shopping website of "Vente-Privée". Since 2008, the electronic commerce for Chinese has been emerging like mushrooms, and a large number of luxury shopping websites have been introduced successively. The more famous ones are: Xiu, 5Lux, Shangpin, Jiapin and Vipshop.

The Market Data Monitoring Report on Chinese Electronic Commerce in 2012 (First half year) released by China Electronic Commerce Research Center shows that the scale of Chinese luxury online shopping market has reached 10.7 billion Yuan from 6.4 billion Yuan in 2010 with a growth rate of $67.2 \%$. However, this set of optimistic data does not show the development status of the Chinese luxury electronic commerce. In fact, the Chinese luxury electronic commerce is undergoing a new turn of reorganization and shuffling, various luxury electronic commerce companies are exploring corporate transformation ways and making timely adjustments according to the market reactions. Among them, the most representative is the cooperation between Xiu and Ferragamo. On October 11, 2012, the well-known international luxury brand Ferragamo achieved cooperation with Xiu and formally authorized it as its official authorized online shop. In fact, the major luxury electronic commerce companies are actively seeking brand licensing. Cooperating with international first-class brands not only is a powerful guarantee for supply channels, but also enhances the trust degree of electronic commerce companies in the minds of consumers, which has great significance for the brand development of luxury electronic commerce companies.

\section{THE CHINESE ELECTRONIC COMMERCE CAN HELP INTERNATIONAL LUXURIES TO REALIZE CHINIZATION IN THE FOLLOWING ASPECTS}

\section{A. The chinization of product design}

More and more international luxury brands transfer their focus to China, and customizing products for the Chinese market becomes one of the strategies commonly used by major brands. Chinese-style red, the traditional Chinese "Dragon" element, and Chinese cheongsam style ... an increasing number of international luxury brands are crazy for China. However, the international luxury brands may not be able to fully grasp the mysterious Chinese market. At this time, the luxury electronic commerce rooted in China can provide valuable reference information on the aspects of their product designs.

For instance, Gucci launched a heart handbag of modern version in 2008. This handbag sold well in mainland China, but was slowly moving in the United States. 5Lux purchased all the inventory handbags in U.S. warehouse, and they were all sold out online in the way to China. In this regard, Sun Yafei, the CEO of 5Lux explained: the fashion consumers in the United States do not like the fancy things, while Chinese consumers are particularly fond of this sweet-feeling bag. It can be imagined that 5Lux can predict market reaction in advance for Gucci, and this heart handbag of modern version is likely to become a product tailored for the Chinese market to achieve greater success.

\section{B. The chinization of circulation}

In recent years, the competition among international luxury brands for the Chinese market has not only stayed in the first- and second-tier cities. With the rapid urbanization speed of low-tier cities in China, the second- and third-tier cities have become new growth points for international luxury brands. In January 2011, the famous international luxury brand LV (Louis Vuitton) entered in Zhengzhou, Henan, which is regarded as symbol that LV entered the second-tier city in China. With more and more famous luxury brands enter the second- and third-tier cities in China, the competition among international luxury brands in the second- and third-tier cities in China also becomes more and more intense. However, as the development of second- and third-tier cities in China is very uneven, the luxury brands do not know these areas well, and research on consumer behavior is inadequate, international luxury brands are careful in making decisions to open shops in the second- and third-tier cities. From this point of view, the Chinese electronic commerce companies can take advantage of their valuable database resources to analyze the main gathering 
places of customers and find out the potential markets so as to provide valuable reference information for the international luxury brands to avoid serious mistakes in selecting target cities and reduce investment risk, and eventually help them achieve channel upgrading.

As for the chinization of circulation, the International luxury brands need to focus on not only the channel upgrade, but also the promising e-commerce business model. More and more international luxury brands are beginning to have their e-commerce sites in Chinese version. Moreover, a lot of brands open e-commerce window in Chinese luxury ecommerce platforms. For this point, international luxury brands can utilize the current mature e-commerce models of Chinese e-commerce companies to enter the field of electronic commerce by cooperating with them, which is undoubtedly a good choice of brands to save time and efforts.

\section{The chinization of marketing communication}

The luxury industry report released in February 2012 by Guosen Securities (Hong Kong) points out: over 60\% of the growth in Chinese luxury market is from the new consumers. How can the luxury brands win the favor of the potential consumers and transform them into new consumers for their brands? Besides their products and services, one critical point is marketing communication strategies of the luxury brands. How can luxury electronic commerce help international luxury brands in this regard?

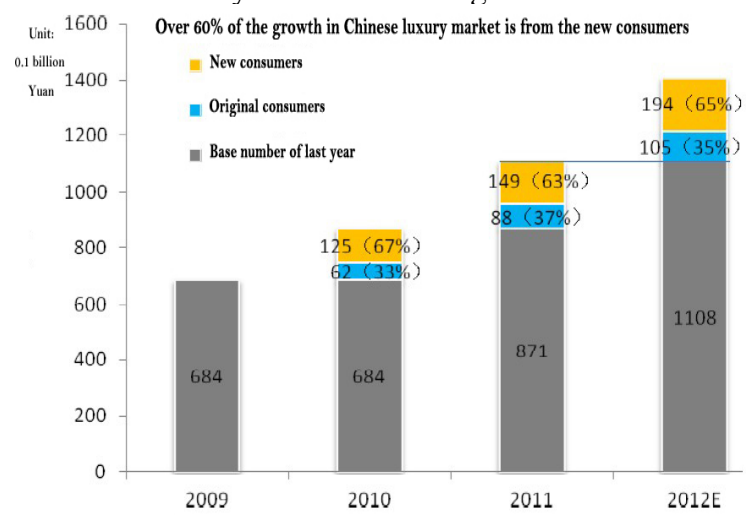

Figure2. Over $60 \%$ of the growth in Chinese luxury market is from the new consumers (Data source: Wind, Guosen Hong Kong)

- Firstly, Internet has quickly developed into the second largest information channel for fashion consumer goods. As a sales platform for luxuries, luxury ecommerce can show consumers the summarized information on luxuries, which help the international luxury brands to promote products and brands with less investment. In addition, the most charm of the luxuries lies in its unique brand culture connotation, in which the brand heritage story is the most prominent. International luxury brands can make use of the Chinese e-commerce platform to spread the founding history of the brands and tell the legendary story of the brands to promote the understanding of the Chinese consumers on the brands.

- Secondly, e-commerce platforms mostly are able to offer discounts, which is very attractive to the Chinese white-collar workers who have relatively low income but with psychological reasons for showing off the consumption or social consumption for the international luxury goods. Moreover, the service of returning or exchanging products within 7 days for no reason dispels the worry of some potential consumer groups and makes them to conduct purchase attempt. Besides, this also offers international luxury brands the opportunity to develop this part of customers into brand loyal consumer groups.

- Finally, Research Report on Chinese Luxury Market in 2011 released by Bain Capital points out: 55\% of Chinese luxury consumers are between the 25 years old to 34 years old, which is 15 years younger than the global average age. In order to meet the younger trend of the Chinese luxury consumers, the spread of luxuries also pays more and more attention to this group who loves social networking platforms. Therefore, the international luxury brands can utilize the current social networking platforms of Chinese luxury e-commerce companies. For instance, Vipshop opened the special column for "Invite Friends" so as to find more potential consumers.

\section{HOW SHOULD INTERNATIONAL LUXURY BRANDS SELECT LUXURY E-COMMERCE COMPANIES}

If international luxury brands can make good use of the various resources of the Chinese e-commerce companies by cooperating with them, they will certainly feel more powerful and convenient in the chinization process of brands. However, the first-class luxury brands also should think twice in selecting cooperative e-commerce companies, for it is not an easy task to find e-commerce platforms really suitable for the future development of the brands.

In selecting the e-commerce platforms, international luxury brands should consider the following aspects:

- First, luxury e-commerce companies can provide information reference value for the brands. The database resources, marketing strength and even the personal ability of the policymakers of luxury ecommerce companies should be considered by international luxury brands.

- Second, consider its neighbors, that is, consider the brand aggregation of the e-commerce companies. It is known that "one takes the color of one's company". With international first-line brands for neighborhood, it can not only enhance the quality feel of the brand itself, but also transfer the original high-end customer base of the e-commerce sites to its own potential customer base, playing an agglomeration effect. Otherwise, the brand image will be greatly degraded.

- Third, think about if the luxury e-commerce platforms have perfect logistics system and online \& offline services. A very important reason for people to buy luxuries is the excellent services, therefore, the services of luxury e-commerce platforms shall not disappoint consumers. In addition, luxuries must be sent to the hands of customers without any damage during the delivery. Due to the high prices of luxuries, 
consumers will pay more attention to it. If the ecommerce platforms do not have perfect logistics system, and can not control the various risk factors during the delivery, they may not only harm the interests of consumers, but also reduce trust degree of consumers on the luxury brands and e-commerce platforms, damaging the images of both parties.

Implementing the chinization strategy has a very important significance for the development of international luxury brands in China. The rapid development of electronic commerce in China is commonly seen. If international luxury brands can find Chinese electronic commerce companies really suitable for the development of their brands, and cooperate with them, it will certainly help to promote the chinization process of the brands. Based on the profound analysis of the Chinese markets, this paper lists the multiple aspects that Chinese electronic commerce companies can assist the chinization process of international luxuries, which provide new ideas for the chinization process of international luxuries.

\section{REFERENCES}

[1] Q.G Shao, "Analysis on the Luxury Marketing Strategies under the Network Environment, "Science Technology and Industry.2011.

[2] X.H Xiong, "Chinese Transgene of Luxury Brands, "China Business Journal.2012.

[3] Y. Yan, "How Far Can Luxury Electronic Commerce Go," Investment and Cooperation.2011.

[4] Y.W Zhao, J.L Lou, "Luxuries Walk into Deeper Chinization," International Finance News.2012.

[5] Y.M Wang, "Luxury Retail Industry: Different Scenes of Domestic and Overseas Markets, Double Era Have Been Met," Industry Report.2012.

[6] H.Y An, W.R Di, Y.Q Wu, "The Rise of the Chinese Luxury Market," China New Time.2011. 